\title{
EL CUIDADO DE SÍ COMO VÍA DE SUPERACIÓN A LA SUBJETIVACIÓN NEOLIBERAL ${ }^{1}$
}

\author{
Claudia Donoso $S$. \\ Facultad de Ciencias de la Salud \\ cldonoso@utalca.cl
}

\begin{abstract}
RESUMEN / ABSTRACT
El presente manuscrito intenta, a través de una sucinta reflexión, dar cuenta de cómo el cuidado de sí rescatado por Foucault podría ser comprendido como una alternativa para superar los mecanismos identitarios de control neoliberal, gracias a la relación activa que el sujeto desarrolla con la verdad. En el entendido de que el abandono del espacio de la norma y el conocimiento por parte de aquella, y su ubicación al servicio de la autoconformación del sujeto favorecería el desarrollo de una relación plena y coherente de cada individuo consigo mismo.
\end{abstract}

PALABRAS CLAVE: cuidado de sí, verdad, subjetivación, parrhesía, neoliberalismo.

\section{SELF-CARE AS A WAY TO OVERCOME NEOLIBERAL SUBJECTIVATION}

This manuscript attempts, through a succinct reflection, to realize how Foucault's theory of the Care of the Self could be understood as an alternative to overcome the identity mechanisms of neoliberal control, thanks to the active relationship that the subject develops with the truth. In the understanding that the abandonment of the space of the norm and the knowledge of that, and its location at the service of the self-formation of the subject, would favor the development of a full and coherent relationship of each individual with himself or herself.

KEYWORDS: Care of the Self, truth, subjectivation, parrhesia, neoliberalism.

En las primeras páginas del libro que reúne las conferencias dictadas por Foucault en los años setenta, aparece la siguiente reflexión:

Al no ser la razón el principio que fundamenta y organiza la realidad, sino el juego de fuerzas activas y reactivas, la verdad no será revelamiento de lo que estaba oculto en nuestra alma ni adecuación con un objeto o un ideal, sino más bien, el resultado de una relación estratégica, y como tal signada por la violencia, la lucha, la desarmonía y el conflicto (Foucault 1999, pp. 177, 183). 
el poder se incardina en los cuerpos, en las prácticas, en los gestos de los seres humanos, pero también en los pensamientos, en las representaciones y en las racionalizaciones y hasta en el propio reconocimiento de nosotros mismos. Por esto cuestionar las formas capitalistas de vida implica conocer las formas insidiosas mediante las cuales operan poderes y saberes específicos, pero a la vez asumir en nuestra propia existencia la renuncia a un reconocimiento, a una identidad que nos ha sido asignada. La lucha contra el poder implica la elaboración de una ética alternativa de la existencia (1999, pp. 17-18).

Por lo tanto, si hablamos de una alternativa no estaremos aludiendo a la tipología existencial moderna, ya definida de manera práctica por los regímenes de verdad simbolizados en las técnicas de producción, significación y dominación; o ya, por las formas de juego teórica expresadas en los semitrascendentales prescritos por la naturaleza (vida), el intercambio (trabajo) y el discurso (lenguaje), sino que por el contrario, de lo que estamos hablando es de una existencia comprendida como libertad. Específicamente, como libertad creadora de un nuevo ethos que, rebasando dicha analítica de la finitud, sus mecanismos de gobierno y los tipos de individuación o técnicas de sí adscritas a este, pueda orientarse hacia la "autoconformación artística de la propia subjetividad" (Foucault 1999b, pp. 18, 393; 2002, p. 484; Sauquillo 2017, p. 74).

Así, contrariamente a la prisión, al taller, al asilo, al hospital, a la escuela, al cuartel, a la fábrica o al psiquiátrico, esta ética alternativa de la existencia no buscará convertir a los individuos en objetos de conocimiento y, al mismo tiempo, en sujetos de dominación, ya mediante el disciplinamiento de los cuerpos o ya a través de la normalización de las poblaciones. Sino más bien lograr, mediante un acto de ruptura con el sistema de reglas imperante, que cada cual se transforme en sujeto de su propia voluntad (Castro 2008, p. 416).

$\mathrm{Al}$ respecto, si cada época se caracteriza por un específico régimen de verdad ${ }^{2}$, que mediante un conjunto de reglas discrimina ficticiamente lo verdadero de lo falso, y "los verdaderos efectos políticos del poder", que determinan los modos de hacer y de ser de los individuos, es perfectamente posible, dada la relación activa que se tiene con la verdad, que esta abandone el espacio de la norma y el conocimiento para situarse en un lugar donde el código se desdibuja y la autotransformación adquiere protagonismo. De esta manera, frente al primer nivel, en el que las relaciones que establecemos con la verdad se hallan mediadas por el saber científico, y también en contraste con el segundo nivel, en el cual las relaciones que formamos con la verdad se enmarcan en las estrategias de individualización, el tercer estadio apunta a las relaciones que desarrollamos con la verdad en función de una práctica orientada al cuidado de sí (Castro 2008, pp. 415418; Foucault 1999, pp. 54, 177, 183).

2 Si bien el cuidado sí se extiende desde el siglo V a.C. hasta el siglo V d.C., esta reflexión se centrará en el periodo que experimenta su mayor esplendor, a saber, entre los siglos I y II d.C. (Foucault 2002, pp. 29, 130). Foucault señala que el cuidado de sí en este periodo se desliga del objetivo de gobernar a los otros, tal como lo podemos observar en el relato 
En este escenario, y contrariamente al cogito moderno que fragmenta a la razón del sujeto de conocimiento -ya que la coincidencia entre creencia y verdad se adquiere en la evidencia-, la práctica del cuidado de sí, como eje fundamental para el desarrollo de una ética entendida como libertad, persigue precisamente lo contrario, es decir, el desarrollo de una ligazón entre sujeto y verdad. Relación que, cabe destacar, no tendrá por principio fundamental el sometimiento del individuo a una ley, a una disciplina, a una norma social o a un valor trascendental, sino el de lograr la subjetivación -gracias al libre desarrollo de toda una askésis orientada al ejercicio de sí mismo en el pensar ajustado al arte de vivir- de aquellos discursos de verdad necesarios para establecer una "relación adecuada, plena y consumada consigo mismo". Ello quiere decir, que sujeto y verdad no se anudan exteriormente, debido a una necesidad trascendental, a un destino fatídico o a una evidencia externa constatable, sino a partir de "una elección irreductible de existencia", es decir, subjetivación y no sujeción de la verdad, y donde el otro juega un rol fundamental. Aquí, precisamente, es donde surge el tema de la parrhesía en su desplazamiento específico de la "práctica individual de la formación del ethos" (Foucault 1999b, p. 277; 2002, pp. 191, 306, 316, 475, 483, 497, 501; 2010, pp. 82-83; 2017, p. 81).

Más concretamente, la parrhesía "caracteriza el discurso del otro en el cuidado de sí”, pues, si la verdad que esta epimeleia heautou busca subjetivar-ya que uno no podrá cuidar de sí sin conocer- no tiene otra finalidad que la de dotar a cada individuo de algo que no tiene, a fin de que con ese algo $^{3}$ pueda enfrentar las dificultades y externalidades que impiden el tránsito hacia el estatus de un sujeto definido por la "plenitud de la relación de sí consigo", es claro el rol fundamental que juega la intervención del otro. Sin embargo, aquel otro, ya en su forma específica de maestro, amigo o director de conciencia, deberá realizar su tarea de forma tal, que no se de cabida ni a la dependencia ni al control del aprendiz (Castro 2008, pp. 266, 418-420; Foucault 2002, p. 133; 2017, p. 41). Por esto, “el discurso del maestro es verdadero, precisamente, en la medida en que el discípulo, después de interiorizarlo, puede prescindir de la relación con él y desarrollar el cuidado de sí mismo en completa independencia" (Castro 2008, p. 266). Así, este "decirlo todo", este libera oratio o este "hablar franco" del maestro o del amigo, no se define por una estrategia de convencimiento o demostración, sino por una crítica necesaria para hacer mejor al otro y, avalada a su vez, por la concordancia

del Alcibíades, a una práctica integrada en la fórmula general del arte de vivir. En este sentido, el cuidado de sí no es entendido como una preparación momentánea o preliminar, sino más bien como una práctica que debe recorrer toda la existencia, que además se realiza sin el mundo ideal como referencia, que no implica una liberación respecto del cuerpo, y donde su elemento fundamental no es el conocimiento sino el ejercicio, la práctica, la askésis. En pocas palabras, el cuidado de sí se constituye en un principio incondicionado y aplicable a todos, que busca otorgar al individuo las herramientas que le permitan enfrentar las dificultades a lo largo de su existencia (Foucault 2002, pp. 129-130; Sauquillo 2017, pp. 421-422, 438-439, 444).

3 Expresado en la forma de un principio interior que guía la acción. 
existente entre el sujeto hablante y la verdad que enuncia (Foucault 2002, p. 386; 2017, pp. 83, 85).

En este punto notamos que esta inquietud o cuidado de uno mismo, ejercido a través de la práctica parresiástica, no busca sustraer al yo del mundo, sino que, gracias al equipamiento otorgado por este conjunto de verdades, situarlo correctamente en aquel. A fin de que a partir de esta ubicación correctamente situada, pueda establecer una regla de limitación con todas aquellas externalidades que impiden el desarrollo de una relación coherente de sí consigo. De ahí precisamente la importancia de recuperar el cuidado de sí, como posibilidad de resistencia al interior de las relaciones de sujeción ejercidas por el poder, y de ahí justamente también, la relación indisoluble entre podergubernamentalidad-gobierno de sí y relación de sí consigo (Foucault 2002, pp. 247, 507-508, 511; Sauquillo 2017, pp. 415, 417).

En este escenario, y reconociendo el grado cada vez mayor de homogeneización que el poder normalizante impone a los sujetos y los grupos, es claro que cuando hablamos de una ética alternativa de la existencia, lo que se propone es nada más y nada menos que una lucha "cara a cara con el poder y contra el poder". Lo primero, porque el cuidado de sí como ejercicio de autogobierno, no niega la existencia del poder ni de los juegos de verdad. Más bien lo que propone es que al interior de estos juegos de poder jugar con el mínimo grado de dominación, y que los discursos derivados de estos regímenes de verdad, sin negar el perspectivismo y constructivismo inherente a ellos, planteen una propuesta alternativa, la cual no tendrá por finalidad dirigir la conducta del otro ni menos transitar hacia un estado de dominación (Castro 2008, pp. 441, 446; Foucault 1999b, pp. 409, 412), sino que por el contrario, propugnar el desarrollo de una serie de "prácticas de libertad que permitan articular formas válidas y aceptables de existencia individual y colectiva" (Castro 2008, p. 441).

De igual manera, este cuidado de sí no desconoce la lucha inherente al proceso de autoconformación, pues entiende "que uno se modela a sí mismo en relación con formas de sujeción" (Castro 2008, p. 178). Ello quiere decir que la libertad asociada a este proceso de autocreación, no supone la ausencia de determinaciones ni su ubicación en una esfera exterior, pues si cada individuo actúa al interior de un juego estratégico de relaciones de poder, que a su vez lo constituyen como sujeto operativo, "la libertad no es una lucha por llegar a ser lo que somos, sino una labor de desprendimiento de la identidad que se nos impone" (Castro 2008, p. 442). En este sentido, si las relaciones de poder corresponden a "formas de conducción de conductas que necesitan, para operar, la virtualidad del comportamiento (...) debe existir la libertad para que el poder se ejerza" (Castro 2008, p. 443). Consiguientemente, si la libertad es consustancial al ejercicio del poder, también lo serán las contraconductas, es decir, aquellas líneas de fuga, puntos o focos de resistencia que, apoyándose en los mecanismos de sujeción, rebasan los límites de captura abriendo un nuevo campo de relaciones de poder y prácticas de libertad.

En consecuencia, si el cuidado de sí constituye el punto a partir del cual combatir los mecanismos de control y sometimiento, y también, el momento a partir del cual dar el salto hacia la creación de nuevas formas de subjetividad, esta estética de la existencia 
supera lo estrictamente personal y se proyecta al ámbito de lo político (Castro 2008, pp. 443-447, 450-455). O sea, este cuidado de sí, ejercido a través de la práctica parresiástica, no solo permitirá el desarrollo de un modo de vida radicalmente otro ${ }^{4}$, sino que también propondrá el despliegue, producto del vínculo que la vida soberana establece con el otro y lo otro, de un nuevo proyecto de mundo relacional dirigido a la superación del atomismo de la producción biopolítica del capitalismo tardío (Castro 2008, p. 493).

Ahora bien, si el cuidado de sí no es un trabajo que el sujeto pueda articular en soledad, sino más bien ha de ser comprendido como una práctica social -pues es precisamente en la confrontación con la alteridad que el sujeto accede a la diferencia que permite la conformación estética de la propia subjetividad-(Castro 2008, pp. 489490; Foucault 1992, p. 51), la descomposición progresiva del ámbito público ${ }^{5}$, junto a la reclusión de los sujetos en actividades insertas en la esfera de lo privado (Arendt 1997), no parece ser una cuestión circunstancial. En el entendido, de que precisamente estas limitaciones son las que afectarían directamente el automodelamiento artístico de la subjetividad. Al respecto, la despolitización de la cultura narcisista, o mejor dicho, la limitación de "la lógica de lo político a la regulación, el control, la gestión y el gobierno de los individuos" (Castro 2008, p. 477), no ha hecho otra cosa que detener el flujo artístico de la autoconformación e instaurar la norma.

De esta manera, así como a partir de los siglos IV-V el cristianismo, condenando la imperfección e instaurando una vida reglada de renuncia, bloqueó la libre construcción de la subjetividad. Y así como trece siglos más tarde el Estado, desarrollando una nueva organización del poder pastoral, implantó su matriz individualizante sobre los cuerpos y las poblaciones. Hoy en día, los sistemas de poder industrial y financiero producen, junto a sus productos y mercancías, una nueva forma de existencia, en la cual la competencia es la "norma de conducta", y la empresa el "modelo de subjetivación" (Laval y Dardot 2013).

En este escenario, fue precisamente el tránsito desde la sociedad disciplinaria, con su "disciplinamiento corporal" que, sin perder la disciplina impuesta, evolucionó

$4 \quad$ Que como tal no buscará emular la epistrophe platónica, es decir, aquella experiencia a través de la cual el alma, mediante un acto de reminiscencia regresa a la perfección del ser; ni tampoco la metanoia cristiana en la cual el yo, producto de un estremecimiento del espíritu, renuncia a sí mismo. Por el contrario, de lo que hablamos cuando aludimos a una existencia radicalmente otra, que además llevará a la instauración de un mundo otro, es de una conversión que busca, volviendo la mirada hacia sí, alcanzar una liberación dentro del mismo eje de inmanencia de este mundo. O sea, ni liberación de este mundo, para alcanzar una realidad luminosa donde opera la verdad, ni tampoco renunciamiento al yo, sino más bien, apropiación activa de ese yo a partir del cual desplegar un nuevo proyecto de mundo (Foucault 2002, pp. 208-209, 216-217, 219, 268).

5 La esfera de lo público constituye el lugar donde actuamos, es decir, el ámbito donde iniciamos nuevos procesos que, al estar insertos en una trama ya existente de relaciones humanas, desencadenarán una serie de reacciones que, por su novedad, afectarán la imagen que el sujeto tiene de sí mismo (Arendt 1997, pp. 19-21). 
hacia la de la normatividad, y más tarde en dirección a la del rendimiento con su "optimización mental" expresada en la forma de una "autoexplotación total"6 (Han 2012, pp. 17,19), lo que permitió bloquear cualquier resistencia o estado de extrañeza que pudiera obstruir el torrente de la nueva razón empresarial. Misma que, gracias a los procedimientos cuidadosamente elaborados de su bioascesis, buscará dotar al individuo de una identidad forjada desde la fragilidad de las apariencias y el deseo consumista, pues el renunciamiento previo del yo permitió modelar una subjetividad completamente entregada al control (Castro 2008, pp. 350-351, 474-475). De esta manera, a diferencia del régimen disciplinar organizado como un cuerpo, y su panóptico perspectivista generador de una consciencia de la vigilancia, el neoliberal, tomará la forma del alma, y cuyo sinóptico digital será construido y mantenido por los mismos moradores que exhibiendo sus deseos - mas no por una coacción evidente, sino disfrazada en la forma de una necesidad autoimpuesta- volverán su vida transparente, y como tal, predecible y calculable (Han 2014, pp. 28, 29, 33).

Mas no todo está dicho ni la novedad se ha erradicado, porque la misma valoración del presente, o sea, esta misma ontología crítica, nos liga inevitablemente al esfuerzo de imaginar el mundo de otra manera. Recordemos que la libertad está por todas partes, y que poderes y resistencias se encuentran diseminados en una misma trama relacional. ¿Acaso no fueron estos mismos nudos de resistencia los que obligaron al modelo pastoral a mutar y transitar hacia el de la soberanía, más tarde al del biopoder y seguidamente al del psicopoder? ¿Acaso no son estas mismas zonas de fuga las que, independientemente de su pervivencia temporal, nos corroboran el hecho de que diciendo la verdad nos transformamos a nosotros mismos y con ello al mundo? ¿Acaso no han sido estos discursos insultantes dirigidos al poder lo que

6 Esta nueva razón de mundo exigirá a cada individuo autoconceptualizarse como un empresario portador de un capital, que debe ser revalorizado a través de la competencia constante con los otros empresarios que conforman el tejido social (Foucault 2007, pp. 262-281). Luego, esta mutación del ciudadano en un perfecto consumidor de productos y servicios, supuestamente orientados al mejoramiento del capital personal, y como tal, prometida fuente de sentido y felicidad, es la respuesta que la misma sociedad ofrece para resolver las necesidades de autoidentificación y autodeterminación, así como para enfrentar el desmantelamiento perpetrado por el capital sobre los derechos de protección social, que tranformó bienes, habitualmente vinculados al estatus de ciudadano, en transacciones entre un comportamiento esperado y una prestación, o bien, en un costo o una deuda asumida directamente por el usuario (Laval y Dardot 2013, p. 387). Imposición crediticia que, independientemente para lo que se destine, implicó, e implica, un trabajo del sujeto "sobre sí mismo", a saber; sobre su cuerpo, al disponer las capacidades físicas e intelectuales comprometidas en el trabajo, y sobre su mente; para convertirlo en capital humano, "empresario de sí mismo", "máquina idónea", evaluable, predecible, calculable, manipulable, sujeto crónicamente culpable, objeto auto-disciplinable capaz de prometer el reembolso de la deuda adquirida, y con esto, permitir un aprovechamiento del futuro al limitar el ámbito de elección del deudor a la lógica crediticia. La deuda se convierte así en "deuda de existencia" (Lazzarato 2013, pp. 48, 52, 57-58, 67, 101, 105, 108). 
lleva a este -utilizando la misma jerga que tradicionalmente ha empleado para excluir o transformar a los sujetos- a calificar de locos, delincuentes, enfermos, anormales, desviados, enemigos de la nación, a todos quienes desafían los discursos de verdad y establecen una línea de ruptura con la forma habitual de existencia, con sus leyes, sus valores, sus costumbres, sus reglas y sus hábitos? Los que en resumidas cuentas, reconociendo que "no hay otro punto, primero y último, de resistencia al poder político que en la relación de sí consigo" detentan el coraje cínico del decir veraz (Castro 2008, pp. 364, 445, 449; Foucault 2002, p. 246; 2010, p. 246, 363-365).

\section{Referencias bibliográficas}

Arendt, H. (1997), ¿Qué es la política? Barcelona: Paidós.

Castro, R. (2008), Foucault y el cuidado de la libertad: ética para un rostro de arena. Santiago de Chile: Ediciones LOM.

Foucault, M. (1992), Historia de la sexualidad 3: la inquietud de sí. México: Siglo Veintiuno Editores.

(1999), Estrategias de poder. Obras esenciales, volumen II. Barcelona: Paidós.

(1999b), Estética, ética y hermenéutica. Obras esenciales, volumen III. Barcelona: Paidós.

(2002), La hermenéutica del sujeto. Curso en el Collége de France (1981-1982), México: Fondo de Cultura Económica.

(2007), Nacimiento de la biopolítica. Buenos Aires: Fondo de Cultura Económica.

(2010), El coraje de la verdad: El gobierno de sí y de los otros II. Curso del Collége de France (1983-1984). Buenos Aires: Fondo de Cultura Económica.

(2017), Discurso y verdad: conferencias sobre el coraje de decirlo todo. Grenoble, 1982/Berkeley, 1983. Buenos Aires: Siglo Veintiuno Editores.

Han, B. (2012), La sociedad del cansancio. Barcelona: Herder.

(2014), Psicopolitica: neoliberalismo y nuevas técnicas de poder. Barcelona: Herder.

Laval, C. y P. Dardot (2013), La nueva razón de mundo: ensayo sobre la sociedad neoliberal. Barcelona: Gedisa.

Lazzarato, M. (2013), La fábrica de hombre endeudado: ensayo sobre la condición neoliberal. Madrid: Amorrortu Editores.

Sauquillo, J. (2017), Michel Foucault: poder, saber y subjetivación. Madrid: Alianza Editorial. 